Running Head: NORMAL MENTAL PROCESSING AND RESISTANCE

Normal Mental Processing of Fundamental Notions And Resistance To Changing One's Thinking: Implications for Psychotherapy Brian R. Johnson Claremont Behavioral Studies Institute 
Normal Mental Processing 2

\begin{abstract}
The author proposes that both the internalized representations of the world (and the self) and the notions used for interpreting these schema tend to be resistant to change, even if observations contradict these notions. Applying Piaget's concepts of assimilation and accommodation as narrowly defined and re-interpreted in terms of Theory theory both the process by which faulty thinking is maintained and the condition accounting for a change in underlying schema are discussed. The importance of confusion in the process of modifying old notions that cause faulty thinking is stressed, and a clinical example is given to illustrate this.
\end{abstract}


Normal Mental Processing of Fundamental Notions

And Resistance To Changing One's Thinking:

\section{Implications for Psychotherapy}

Practicing clinicians are often confronted with their clients' resistence to changing salient, false beliefs held about themselves and the worlds. Even with the advancement in cognitive oriented therapies, there are certain self defeating notions that people have a hard time giving up.

What I propose in this paper is that this resistence is neither a reflection of pathological thought processing nor, in most cases, resistance in the traditional sense of the term. What clinicians confront is a fundamental mental mechanism that controls the way new information is processed to conserve and protect existing belief systems; i.e., complexes of notions that at one point were often adaptive to the holder (Johnson,1995b).

The mechanism that I offer to account for expectable resistence comes from developmental psychology and was first identified by Piaget (Piaget, 1981; Piaget \& Inhelder, 1969) and has recently been refined by Gopnik, Meltzoff and Kuhl (Gopnik, Meltzoff and Kuhl, 1999; Gopnik, 1996a; Gopnik, 1996b; Gopnik and Meltzoff, 1996). This mechanism can be identified as what most psychologists know as assimilation and accommodation.

A Little Personal Background

To appreciate the application of these constructs to 
Normal Mental Processing 4 clinical resistence, I need to begin by refreshing the reader about the traditional use of these constructs and their application to adult circumstances. To do that let me recount two personal experiences.

When, as an undergraduate and enrolled in an introductory course to developmental psychology, I decided to use one of Piaget's paradigms to measure my children's understanding of conservation. As predicted, my three year old incorrectly observed that there was more water in the tall glass than in the stout glass although a moment before she had noted that there was the same amount of water in another stout glass from which I had poured all of the water into the taller glass. I think my five year old made the same observation. My six year old thought that the whole thing was stupid since obviously there was the same amount of water as before I poured it from the stout glass into the tall glass.

This exercise demonstrated not only the qualitative difference in the thinking of children of different ages but how people's observation and understanding of things is controlled by their notions (schemas) about the world (and of themselves) that they have formed. Years later, I thought of this and remembered my children's trouble with conservation as I was reading stephen Hawking's (1988) A Brief History Of Time. There were concepts concerning the curving of space-time, wave/particle duality, 
Normal Mental Processing 5

black holes and multiple dimensions of space-time that were not consistent with my schema about time or space and were antagonistic to the cognitive operations that I have realized gave me a sense of mastery of the physical world. My children were not aware that their schema did not support the phenomena they were observing (conservation). I certainly was. Confused, I read and re-read chapters, paragraphs, and sentences. Some of the stuff I think I finally grasped. A number of these theories I still struggle to understand.

\section{Predictable Misinterpretations}

These two examples illustrate how normal mental functioning can cause people to misinterpret what they observe or cause confusion when they are confronted with a undeniable contradiction between what they are witnessing and what they know or think to be. This first example also illustrates how an assumed sense of cognitive mastery of the environment can interfere with the ability to see things as they really are, a mind set shared by children and adults (Piaget, 1972), manifested in every day life situations and in the therapeutic setting.

Piaget (1981) summarized this process nicely when he stated that "assimilation is that aspect of adaptation which conserves form or organization. Accommodation is that aspect which modifies form as a function of the external situation. Both notions apply to forms of behavior and thought. . " (p. 4). 
Normal Mental Processing 6 Piaget also noted "the filtering or modification of the input is called assimilation; the modification of internal schemes to fit reality is called accommodation" (Piaget \& Inhelder, 1969, p. 6). This process fits the social domain as well as the intellectual (Wertsch 1979). In terms of the ego syntonic distorted views of the world and the self that are a product of growing up in a dysfunctional or abusive environment, we can say that a person who is the product of this background has a set of unverbalized beliefs or convictive schema regarding the world. An example would be: "I belong around people who will use me and take me for granted" (Johnson, 1995a). Experiences from positive relationships are minimized or distorted to maintain the integrity of this old notion; in other words, these experiences are assimilated. This mechanism minimizes confusion.

Dealing With Confusion

Confusion can be defined as an awareness of a disequilibrium between some aspect of the internalized representation of the world and evidence that contradicts that representation. Many people (maybe most) do not like to be confused or uncertain. Some have a high intolerance of uncertainty or ambiguity including high worriers (Ladouceur, Talbot, and Dugas, 1997) and those with generalized anxiety disorder symptoms (Ladouceur, Blais, Freeston, and Dugas, 1998). Most people want to maintain a sense of mastery of their environments; those who do not have 
Normal Mental Processing 7

this sense follow a coping pattern of defensive avoidance (Janis \& Mann, 1977). In the case of my attempt to comprehend Hawking's Brief History of Time, I could have, depending on my personality and mind set, suspended my confusion by concluding that: (1) these theories about time and space were nonsense; (2) they were not important nor worth my time to understand; (3) they were important but I didn't want to take the time; (4) I could conclude that I'm just too stupid to master these matters; (5) this stuff is for other people, not for me; or (6) I could have pretended to myself that I understood the material. All of these would reflect ways of assimilating this challenging book and can be done deliberately but more often automatically without any conscious awareness (see Wegner \& Wheatley, 1999). To accept that I didn't understand and desiring to gain I had to admit that my thinking was getting in the way and I would have to struggle to realize new notions to fit what Hawking was presenting. As exasperating as my confusion was, accepting it as a normal part of the learning process could take some of the sting out of this state of mind. To accept this I would have to have a strong belief that confusion has value in promoting a search for more accurate answers and an accommodation of old schema.

Beyond Piaget

Twenty five years ago, Piaget's theories were still generally accepted. Today things are quite different. Piagetian 
Normal Mental Processing 8

theories, in general, have not stood up to recent empirical investigation (Brainerd, 1996), and, specifically, "Piaget's account of assimilation and accommodation as the basic constructivist mechanisms now seems too vague" (Gopnik, 1996a, p 221). This is not to say the these construct do not have value, but they needed to be refined. It is proposed that when assimilation and accommodation are restated in terms of the newer Theory theory (Gopnik, Meltzoff and Kuhl, 1999; Gopnik, 1996a; Gopnik, 1996b; Gopnik and Meltzoff, 1996) these mechanisms become particularly relevant in understanding the process by which people correct their faulty thinking.

\section{Theory Theory}

Theory theory proposes that children (and adults) function very much like scientists (or more correctly that scientists function very much like children (Gopnik, 1996b) in that they mentally construct theories to interpret, explain, predict, and thereby master their worlds. In a sense each child growing up goes through a personal evolution of thought. Theory theory proposes that the infant is not a tabula rasa nor is the content or form of their intellectual and social development a nativistic forgone conclusion. While the infant comes into the world with certain representations already in place and cognitive devices that provide the potential for redefining these as well as creating new representations and rules, the process of 
Normal Mental Processing 9

development reflects the child's interpretation of what they observe about their environments. From infancy, children form theories. There is research that provides empirical support that this ability in innate (see Gopnik and Wellman, 1992).

What is appealing about Theory theory is the way it accounts for the individuality of development and the way new information is treated. As in science, new evidence that is inconsistent with a established theory is first ignored, discounted or explained away as a fluke or background noise. Later auxiliary theories are formed to account for the contradictory evidence that won't go away. This allows for the preservation and integrity of the primary theory. Finally as more contradictory evidence is realized and more auxiliary theories are tacked on, the system finally collapses under its own weight. A new theory is formed that better accounts for all the evidence (Gopnik \& Meltzoff, 1996).

Some may see theory development as a metaphor when used to describe how a child's thinking evolves. I agree with Gopnik and Meltzoff (1996) that this is not a figure of speech. Kuhn (1996) takes a similiar position and sights no less an authority than Einstein to promote the view that science is no more than a refinement of ordinary thinking. Children (and adults for that matter) do construct actual theories to account for matters that they confront in their worlds. The theories tend to be resistant 
Normal Mental Processing 10 to change but over time are gradually modified to form new theories as the evidence to which the holders are exposed promotes a paradigm shift (Kuln, 1977). To illustrate this let's use the example of a teenager from a family of two alcoholic parents who believes (theorizes) that her family is normal and her experiences pretty much the same as her peers. Let's call her Lisa.

From childhood, Lisa believes that what occurs in her house is pretty normal. Her mother had often said that all families have problems, and her friends who are from reasonably functional families tend to complain, as she does, about their parents. And there are lots of shows on t.v., especially on the Fox Network, such as The Simpsons, Titus, and Malcolm In The Middle, that have left Lisa with the perception that the dysfunction they take as normal, is in fact normal and common place. Her mother and father, practicing and role modeling denial, reinforce this mind set (even when the most outrageous and painful things occur due to her parents' substance abuse).

As Lisa grows older she inevitably realizes that there are problems with her I'm from a normal family theory. The girl notices that when she visits with some of her friends, their parents are nice and don't act sullen and nasty the way her own parents do. Reflecting on this she concludes that they are doing what her own family does: Being well behaved in public or when 
outsiders are in the house (even her father who is unpredictable and hurtful can be real nice at times). Then one day Lisa learns from a girl that another friend, Jessica, who had stayed over night says that she won't go back to Lisa's house because her parents are "drunks" and the place is "creepy." Lisa is greatly upset by this and angrily confronts Jessica. Jessica admits that she said this and, yes, she believes Lisa's parents are alcoholics and she doesn't like being over at her house. This disturbs Lisa, who wonders for a while if her family is really messed up, but soon discounts this by concluding that Jessica is a snob, mean spirited, and a gossip.

As Lisa grows older she is exposed to more and more things that make it harder and harder to believe in her family's normalcy. While Lisa herself does not drink or do drugs, she finds that most of the kids she hangs with do or seem to come from troubled families and, as a group, they are different from the rest of the kids at school. (For a while she figures most teens, except the dweebs, drink or use drugs but are not as obvious about the practice.) One day a friend whose parents also have a problem with alochol invites her to Alateen. She attends a few meetings and eventually concludes that her family is dysfunctional but also concludes that all families are dysfunctional and that hers is really no different. However, things continue to happen to challenge this modified theory. Her 
mother is arrested for driving under the influence and forced to attend A.A. The family is more and more chaotic with her older brother being kicked out of school for drug possession. One night her father makes a sexual pass at Lisa's friend after which hardly any of her friends will come over to her house. Finally the belief no longer holds and Lisa realizes that her family is pretty messed up and not like most. What she has taken as normal family life was neither normal nor healthy.

Given what Lisa observed and understood about the nature of things, her belief progression is logical and even in its own primitive way scientific if we remember that the word scientific comes the Medieval Latin scientificus which means "producing knowledge."

The proposition that man thinks as a scientist is basically what Kelly $(1963,1955)$ proposed, and his personal construct theory is a forerunner of contemporary cognitive therapies (Beck, Rush, Shaw, \& Emery, 1979). While Theory theory is somewhat reminiscent of what Kelly proposed for how people "construed" their worlds, Gopnik, Meltzoff, and Kuhl's model is different, especially in its underscoring of how people can hold onto old notions in face of contradictory evidence. This has important implications for psychotherapy.

Redefining Assimilation And Accommodation

The example of Lisa and her family not only illustrate the 
application of Theory theory but a more specific way of defining assimilation and accommodation. As Gopnik (1996a) notes ". . the interpretive effects of theories seems much like assimilation, and the processes of falsification and counterevidence, which lead to theory change, are reminiscent of accommodation" (p. 221). The girl assimilated what she observed to fit her theory of her family (often by assimilating new notions such as Jessica being a snob) and later changed or accommodated her principle theory (i.e., her family is dysfunctional and different) to better explain the evidence.

I prefer to continue the use of the terms assimilation and accommodation to identify this more exact process. The reason is practical: Most mental health professionals learned in undergraduate (and even graduate level) developmental psychology courses what Piaget generally meant by assimilation and accommodation. An informal survey of current developmental psychology texts (Berk, 1996; Crain, 1992; Dacey and Travers, 1999; Vasta, Haith \& Miller, 1994) revealed that these general concepts are still taught to undergraduates and graduate students and given that these definitions do not require an acceptance of his general theories to be viable and are, in a narrower sense relevant, the terms still have application.

Clinical Application of Assimilation and Accommodation For a clinician to appreciate the full implications of this 
process we need to look beyond a child's changing theories about a family's functionality. Theory theory can also account for the variance in the development of the individuality of belief systems and expectations about oneself. While it is important to understand how substantially different theories are formed in childhood about the nature of world (and the self), for clinicians it is particularly relevant to realize the later impact of this process. To observe this we can look at the experience of a man who was a hyperactive child.

As a boy this man formed the theory from different things his parents said and did that one must be good to be loved. He say how his parents treated his sister who in his eyes was such a good little girl, so smart and respectful. Having a condition that interfered with his ability to behave in ways that were acceptable in the family (paying attention, sitting still, respecting others' property, not hitting his sister when he got mad, etc.) he was often in trouble. Not understanding hyperactivity, his parents didn't know what to do. In frustration and anger they often yelled at him, hit him, and took away his toys. Being punished all the time no matter how hard he tried to be good and loving, he concluded that he mustn't be very nice. As the years went by he developed a theory, a convictive schema, that he was bad and therefore unlovable. He also formed an assumptive schema that the only way he will be loved is to be 
perfect. This created a serious conflict because he had a loving nature, still loved his parents and wanted to be loved by them but he knew that there was no way he would be because he was not good.

The parents finally took the boy to a mental health professional who correctly diagnosed the boy's condition and saw the family's struggle. The parents wanted help and actually loving the boy very much, were willing to do whatever they could to make things better. The boy was put on Ridalin which helped him to concentrate and be less hyper. His parents were given counseling on A.D.H.D. and anger management. Overall things improved considerably. But there were still problems including the boy's insecurity. His parents were not perfect and sometimes they would over react to his behavior. And other kids normally didn't want to play with him. These things came out in therapy . The therapist noted that children with hyperactivity often feel that they are not loved. The boy said that his parents didn't seem to get angry as often as they used to and seemed to do more nice things for him. At first he thought they are being different because the doctor told them to not hit him. Over time as things continued to be better, he began to think that maybe he wasn't so bad after all. But was he good enough to be loved? If he knew the word he might have said that he was being tolerated. We have to be careful not to think of this change as 
occurring with deliberate reflection. Much of this process was done below conscious level (Bargh \& Chartrand (1999); Wegner \& Wheatley, 1999; Epstein, 1994; Johnson, 2000; Kihlstrom, 1990; Piaget, 1972), and much of it that was reflective became, as time went by, "forgotten" without the structures and beliefs inactivated. In other words, the theories as assumptions, beliefs, and expectations still influence behavior although the person cannot verbalize these schema or, if he or she attempts to, be wrong about one's thinking process. Nelson and his associates (Caroll \& Nelson, 1993; Mazzoni \& Nelson, 1995; Nelson, 1996) have demonstrated the faulty thinking a person can maintain about their faulty thinking.

As an adult, this man continues to have difficulties with conflict and intimacy. He tends to be exceptionally considerate of others and is usually liked, but when people display affection, he becomes uncomfortable. Often the relationship with his girlfriend is strained. He becomes distant when she tells him that she loves him. When she confronts this, he admits that he has a hard time with affection. "A guy thing, I guess," he says to minimize the issue. If his girlfriend gets angry at something he does, he is threatened and pulls away. He experiences guilt and, if his girlfriend confronts his avoidance, he snaps back, "What do you except? I'm not a very nice person!" She reacts to this and the relationship melts down. As he would 
say, "the scene felt real familiar."

This man cannot explain way he over reacts the way he does and how come he becomes so distressed when someone is angry at him. He does not see that expressions of affection are not consistent with his sense of being unlovable. He cannot see nor understand how he assimilates these incongruent expressions of affection by distancing himself from the source, his girlfriend. Nor can he explain the anxiety they produce when he cannot quickly discount or minimize them. His pulling away to reduce his anxiety also increases the tension between he and his girlfriend. Her anger in turn provides more evidence to an invisible anticipatory schema: "People will soon enough see how I really am and dislike me." The woman's anger, as painful as it is to experience, also feels normal.

\section{Implications For Psychotherapy}

One application of cognitive psychotherapy can be defined as facilitating accommodation of old, faulty notions. If this man were to enter treatment, he would no doubt be motivated (if not by the insistence of his girlfriend) by the distress caused by this pattern or by an acceptance that his behavior is selfdefeating and out of control. If he expresses confusion, it would likely reflect an inability to understand why he at times becomes so irrational.

For this man to benefit from psychotherapy he must become 
aware of the negative beliefs about himself and his expectation that people will reject him if they really get to know him. This would be a challenging process because not only must he accept that his self view (and view of the world) is faulty (Beck, 1976; Beck, Rush, Shaw, \& Emery, 1979; Beck \& Freeman, 1990), he must become aware of the influence of notions which are largely unconscious and have never been verbalized (Bargh \& Chartrand, 1999; Bargh, Chen, \& Burrows, 1996; Johnson, 2000). It will be more natural for him to assimilate challenges to his distorted implicit schema (by intellectualizing or discounting the process) than to accommodate these old, invisible notions. Applying Theory theory, he would unpremeditatedly attempt to preserve his self theory by explaining away contradictory evidence or finding a way to fit them in. Superficial change may be realized with accompanying symptom relief without adjustment in the schema that underpin his characterlogical thinking and behavior patterns. Accommodation of these requires deeper reflection on his history and the incongruency between how people respond to him and how his behavior reflects distress and a negative belief about himself. If there is enough of the right kinds of evidence that contradict his old theories about love and his being no good and a disappointment and, if the therapist can help the man realize how he has behaved in ways to prove the old beliefs and expectations, his old theories of himself will give, unable to 
support the net of exceptions and auxiliary theories that have been tacked on. Accommodation of these notions can occur with an increased ability to tolerate conflict and intimacy.

The Importance of Confusion In Therapy Confusion is inevitable in the process of modifying old notions that cause faulty thinking, and it is important to be validated. I addressed this in a self-help booklet (Johnson, 1995a) stressing that confusion and the accompanying discomfort are essential elements for growth and real change of old, faulty thinking. To illustrate this I recounted working with a woman who had a strong transference to me. Her experiences from childhood had resulted in forming the theory that there were five types of people in the world: abusers, neglectors, users, rescuers, and rejecters. This woman admitted that she was often confused about me because I didn't fit in her model. "You're not like anyone else," she would sometimes say. What she did not say but believed was, "You really are like others but you haven't shown your true colors yet!" (Johnson, 1995a).

This woman had a hard time dealing with someone who liked her, had a genuine commitment, and, at the same time, maintained reasonable therapeutic limits. She often pegged me as a "rescuer." This was not accurate, which at moments she realized. "You make no sense," she'd say. "A person who cares but doesn't try to rescue me. You just don't fit in." Her confusion about 
Normal Mental Processing 20

me would at times cause her distress and even despair. She would sometime act out, testing limits in ways that, in a nontherapeutic relationship, would have more likely than not created a self fulfilling prophecy. This was an old pattern for her. Many would befriend or rescue her. But soon these individuals would get burned out and begin to neglect, reject, or even abuse her.

This woman's behaviors reflected these instilled notions about people; she expected to be caught in these frustrating and hurtful relationships, although she wished for a different type of relationship. People who would not tolerate being set up would distance themselves which she perceived as rejection. Her experience with me put a real strain on her old notions.

Through much of the therapy this woman looked at me as a fluke, an exception. (That was one way to reduce her confusion and maintain her old theory) But over time, as she struggled with my and other's appropriate behavior, accommodation occurred. The shift was reflected in a remission in confusion and a new found comfort around certain people including me. She began to see that while there were people who are neglecting, abusive, rejecting or rescuers, there were also people who can care and will be there for her, without trying to run her life or change her, if she would not put unreasonable demands or expectations on them. 
Conclusion

In this paper I've attempted to affirm that change in faulty thinking, that is reflective of deep, fundamental, and often invisible notions, is possible but that change is often more challenging and unintentionally resisted than is often implied by cognitively oriented psychotherapies (Ellis, 1994; Ellis \& Harper, 1975; Beck, 1976; Beck, et al., 1979; Beck \& Freeman, 1990). As Theory theory proposes we are wired to process contradictory evidence in a way that causes us to ignore, discount or treat that evidence as a special case. There is evidence that this tendency is greater for adults than children. Gopnik and Meltzoff (1996) note that "except for the case of science, such conceptual changes are quite rare in ordinary adult life" (p 30-31). They speculate that "once, as children, we have engaged in the theorizing necessary to specify the features of our world [and of ourselves], most of us most of the time may simply go on to the central evolutionary business of feeding and reproducing" (p. 20).

Contrary to what Gopnik and Meltzoff state, even in the area of science there is adult resistance to change. How often does a scientist assimilate contradictory data by ignoring it, adjusting it or interpreting it to fit an existing theory? Holton, a physicist and historian of science, stated (Csikszentmihalyi, 1996) : 
Normal Mental Processing 22

It was not true. . that the way to think about science is to think in terms of protocol sentences, and verification theory of meaning, and all those things. . . But these presuppositions were the things that the best of them [scientists] were willing to put their money on, their reputation, their time, their very life, and stick with it even against the evidence for a while. They were enchanted with an idea for which there was in fact no proof. (p. 88). Scientist deal with matters that can be formally tested using the scientific method. People, dealing with the realities of themselves and their lives, are often caught in a whirl of experiences, some contradictory, but much which seems to affirm their faulty belief system with no learned mind set to sort through it all. Cognitive oriented therapy can offer that mind set. Part of what they must learn to do is ask themselves (Johnson, 1995a):

Am I really willing to accept that something I take for granted may be incorrect? Am I sincerely willing to try to look at things differently? Am I willing to put myself in the frame of mind to accept that there are things about myself and the world that I must relearn? Am I willing to commit the effort to apply what I learn to change my behavior? (p.17..18)

It has been my experience that adults tend to be threatened 
by confusion and some can become hostile when a fundamental notion, personal rule or conviction is challenged. Indirectly this stresses the importance of the therapeutic alliance. This involves more than the credibility of the clinician; the psychotherapist must be experienced by the client/patient as a trusted, affirming voice for honesty who can be a guide on a journey away from the obsolete and inaccurate notions of the person's past and to healthier, more correct schema about the world and about oneself. 


\section{References}

Bargh, J. A. \& Chartand, T. L. (1999). The unbearable automaticity of being. American Psychologist, 54, (7), 462-479.

Bargh, J. A., Chen, M., \& Burrows, L. (1996). Automaticity of social behavior: direct effects of trait construct and stereotype activation on action. Journal of Personality and Social Psychology, $71(2), 230-244$.

Beck, A. T. (1976). Cognitive therapy and the emotional disorders. New York: International Universities Press.

Beck, A. T., Rush, A. J., Shaw, B. E., \& Emery G. (1979). Cognitive therapy of depression. New York: The Guilford Press.

Beck, A. T., \& Freeman, A. (1990). Cognitive therapy of personality disorders. New York: The Guilford Press.

Berk, L. E. (1996). Child development. New York: Allyn \& Bacon .

Brainerd, C. J. (1996). Piaget: a centennial celebration. Psychological Science, $7(4), 191-195$.

Carroll, M. \& Nelson, T. O. (1993). Effect of overlearning on the feeling of knowing is more detectable in within-subject than in between-subject designs. American Journal of Psychology, $106(2), 227-235$.

Crain, W. (1992). Theories of development: concepts and applications. Engelwood Cliffs, NY: Prentice Hall.

Csikszentmihalyi, M. (1996). Creativity: flow and the psychlogy of discovery and invention. New York: Harper Collins.

Dacey, J. S. \& Travers, J. F. (1999). Human development across the life span. New York: McGraw Hill.

Ellis, A. (1994). Reason and emotion in psychotherapy, revised and updated. New York: Birch Lane Press Book.

Ellis, A. \& Harper, R. A. (1970). A new guide to rational living. Englewood Cliffs, NJ: Prentice-Hall, 1975.

Epstein, S. (1994). Integration of the cognitive and psychodynamic unconscious. American Psychologist, 49, 709-724. 
Gopnik, A. (1996a). The post-piaget era. Psychological Science, 7 (4), 221-225.

Gopnik, A. (1996b). The scientist as child. Philosophy of Science, 63, 485-514.

Gopnik, A. \& Meltzoff, A. N. (1996). Words, thoughts, and theories. Cambridge, MA: The MIT Press/Bradford Book.

Gopnik, A., Meltzoff, A. N. and Kuhl, P. K. (1999) The scientist in the crib: minds, brains, and how children learn. New York: William Morrow And Company.

Gopnik, A., \& Wellman, H. M. (1992) Why the child's theory of mind really is a theory. Mind and Language, 7 (1-2), 145-171.

Hawking, S. (1988). A brief history of time. New York: Bantam Books.

Hellman, Hal. (1998). Great feuds in science: ten of the liveliest disputes ever. New York: John Wiley and Sons, Inc.

Kelly, G. A. (1955). The psychology of personal constructs. New York: W. W. Norton and Company.

Kelly, G. A. (1963, 1955). A theory of personality: the pschology of personal constructs. New York: W. W. Norton and Company.

Kuhn, D. (1996). Is good thinking scientific thinking. In D. R. Olson \& N Torrance (Eds.), Modes of Thought: Explorations in Culture and Cognition. (pp 261-281). New York: Cambridge U

Kuln, T. S. (1977). The essential tension. Chicago: University of Chicago Press.

Janis, I. L. \& Mann, L. (1977). Decision making: a psychological analysis of conflict, choice, and commitment. New York: The Free Press.

Johnson, B. R. (1995). Getting unstuck: a guide for breaking out of self-defeating patterns. Claremont, CA: Claremont Behavioral Studies Institute.

Johnson, B. R. (1995) Understanding victimization. Claremont, CA: Claremont Behavioral Studies Institute.

Johnson, B. R. (2000). Impressions, images, and ideas 
Normal Mental Processing 26

going beyond the assumptions of cognitive therapy. Manuscript in preparation for publication.

Ladouceur, R., Blais, F., Freeston, M. H., \& Dugas, M. J. (1998). Problem solving and problem orientation in generalized anxiety disorder. Journal of Anxiety Disorders, 12(2), 139-152.

Ladouceur, R., Talbot, F., \& Dugas, M. J. (1997). Behavioral expressions of intolerance of uncertainty in worry. Behavior Modification, 21 (3), 355-371.

Mazzoni, G., \& Nelson, T. O. (1995). Judgement of learning are affected by the kind of encoding in ways that cannot be attributed to the level of recall. Journal of Experimental Psychology: Learning, Memory, and Cognition, 21, 1263-1274.

Nelson, T. O. (1996). Consciousness and metacognition. American Psychologist, 51(2), 102-116.

Piaget, J. (1972). The child and reality. (A. Rosin, Trans.). New York: Penguin Books.

Piaget, J., \& Inhelder, B. (1969). The psychology of the child. New York: Basic Books.

Piaget, J. (1981). Intelligence and affectivity: their relationship during child development. (T. A. Brown \& C. E. Kaegi, Trans \& Eds). Palo Alto, CA: Annual Reviews, Inc.

Vasta, R., Haith, M. M. \& Miller, S. A. (1994). Child psychology: the modern science. New York: John Wiley \& Sons.

Wegner, D. M. \& Wheatley, T. (1999). Apparent mental causation: sources of the experience of will. American Psychologist, 54 (7), 480-492.

Wertsch, J. V. (1979). The concept of activity in soviet psychology. Armond, NY: Sharpe. 